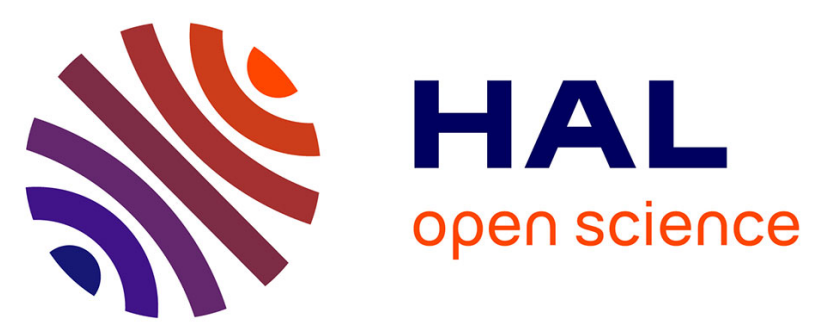

\title{
Early Prediction of Graft Outcomes After Kidney Transplantation From Donors After Circulatory Death: Biomarkers and Transplantation Characteristics
}

Anne-Sophie Truche, Candice Trocme, Sabrina Vergnaud, Bénédicte Janbon, Diane Giovannini, Paolo Malvezzi, Xavier Moreau-Gaudry, Lionel Rostaing, Rachel Tetaz

\section{To cite this version:}

Anne-Sophie Truche, Candice Trocme, Sabrina Vergnaud, Bénédicte Janbon, Diane Giovannini, et al.. Early Prediction of Graft Outcomes After Kidney Transplantation From Donors After Circulatory Death: Biomarkers and Transplantation Characteristics. Transplantation Proceedings, 2019, 51, pp.3234 - 3243. 10.1016/j.transproceed.2019.09.009 . hal-03488541

\author{
HAL Id: hal-03488541 \\ https://hal.science/hal-03488541
}

Submitted on 21 Dec 2021

HAL is a multi-disciplinary open access archive for the deposit and dissemination of scientific research documents, whether they are published or not. The documents may come from teaching and research institutions in France or abroad, or from public or private research centers.
L'archive ouverte pluridisciplinaire HAL, est destinée au dépôt et à la diffusion de documents scientifiques de niveau recherche, publiés ou non, émanant des établissements d'enseignement et de recherche français ou étrangers, des laboratoires publics ou privés.

\section{(ㅇ)(1) $\$$}

Distributed under a Creative Commons Attribution - NonCommerciall 4.0 International 


\section{Early prediction of graft outcomes after kidney transplantation from}

\section{donors after circulatory death: biomarkers and transplantation characteristics}

Anne-Sophie Truche ${ }^{1,4}$ M.D., Candice Trocme ${ }^{2}$ M.D., Sabrina Vergnaud ${ }^{2}$ M.D., Bénédicte Janbon $^{1}$ M.D., Diane Giovannini ${ }^{5}$ M.D., Paolo Malvezzi ${ }^{1}$ M.D., Xavier Moreau-Gaudry ${ }^{3}$ M.D., Lionel Rostaing ${ }^{1,4}$ M.D. PhD., Rachel Tetaz ${ }^{1}$, M.D.

${ }^{1}$ Nephrology Hemodialysis Apheresis, and Kidney Transplantation, Grenoble University Hospital, La Tronche, France

${ }^{2}$ Department of Biochemistry Toxicology and Pharmacology, Grenoble University Hospital, La Tronche, France

${ }^{3}$ Grenoble Dialysis Association AGDUC, La Tronche, France

${ }^{4}$ Université Grenoble-Alpes, France

${ }^{5}$ Laboratory of histopathology, Grenoble University Hospital, La Tronche, France

Author email addresses: astruche@chu-grenoble.fr ; ctrocme@chu-grenoble.fr ; svergnaud@chu-grenoble.fr ; bjanbon@Cchu-grenoble.fr ; dgiovannini@chu-grenoble.fr ; pmalvezzi@chu-grenoble.fr ; xmoreau-gaudry@agduc.com ; rtetaz@chu-grenoble.fr 


\section{Authors' contributions:}

Study design: A-S. Truche, R. Tetaz

Biological measurements: C. Trocme, S. Vergnaud

Data collection: A-S. Truche

Statistical analysis: A-S. Truche, X. Moreau-Gaudry

Paper redaction: A-S. Truche, R. Tetaz, L. Rostaing

Patients' care: B. Janbon, P. Malvezzi, R. Tetaz

Histopathology reading: D. Giovannini

Critical review of the paper: all

\section{Corresponding author}

Pr Lionel Rostaing

CHU Grenoble-Alpes

Avenue Maquis du Grésivaudan

38700 La Tronche

Tel: +33476765523

E-mail: lrostaing@chu-grenoble.fr

Short running title: Prediction of DCD kidney-graft outcomes

Keywords: Kidney transplantation; donor after circulatory death; biomarkers; prediction

Conflict of interest: The authors declare no conflicts of interest. 


\section{$\underline{\text { Abbreviations }}$}

AUC, area under the curve

CKD-EPI, Chronic Kidney Disease - Epidemiology Collaboration

DBD, donor after brain death

DCD, donor after circulatory death

DGF, delayed graft function

DSA, donor-specific antibody

HLA, human leukocyte antigen

IGFBP7, insulin-like growth factor-binding protein 7

KT, kidney transplantation

LD, living donor

ROC, receiver operating characteristics

sLDH, serum lactate dehydrogenase

TIMP2, tissue inhibitor of metalloproteinases 2

uNAG, urinary $\mathrm{N}$-acetyl beta-D glucosaminidase

UNGAL, urinary neutrophil gelatinase-associated lipocalin 


\section{Introduction}

A shortage of kidney allografts has resulted in extending the pool of potential donors, i.e. for example living-kidney transplantation to non-related donors, and organs from donors after circulatory death (DCD), which has been made possible by the development of hypothermicperfusion machines that improve organ preservation. Kidney transplantation using DCDs has shown similar results to those from donors after brain death (DBD) in terms of patient- and graft-survival rates [1], and is associated with enhanced survival compared to patients that remain on dialysis while awaiting a DBD [2]. However, DCD recipients suffer from a much higher rate of delayed graft function (DGF) [3].

DGF is defined as a requirement for dialysis in the first week post-transplantation [4] and is a risk factor in DBD-kidney transplantation (DBD KT) for acute and chronic allograft rejection [5] and decreased long-term graft function [6]. However, the outcome following DGF in DCD KT is uncertain [7]. DGF is mainly caused by ischemic reperfusion injury and its severity depends on factors linked to the donor, the recipient, and graft-storage characteristics (8).

Patients with more serious kidney lesions caused by ischemic reperfusion injury need to be identified to optimize their management: this is a major early post-transplantation objective. The use of baseline characteristics alone (donor age, serum creatinine at graft removal, cold-ischemia time) has limited accuracy to predict early and late allograft outcomes. Unfortunately, serum creatinine cannot be considered as a perfect marker for kidney injury.

An increase in serum creatinine is an indication of extensive kidney damage, whereas tubular damage alone, without subsequent renal dysfunction, is associated with a worse prognosis [9]. In addition, the increase in serum creatinine is always delayed with regards to the injury occurrence: therefore it can be used to diagnose rather than predict DGF [10].

Early biomarkers are needed to improve predicting graft outcomes. Specific urinary markers of tubular injury could be of potential interest. Among these markers, neutrophil gelatinase- 
associated lipocalin (NGAL) has been the most widely studied in living-donors (LD) and DBD KTs [11]. N-acetyl $\beta$-D glucosaminidase (NAG), a lysosomal enzyme, could also be potentially useful for predicting graft outcome [12]. However, these markers have not been used routinely; in patients with DCD KT, the prognostic use of these markers has not been investigated. Two urinary biomarkers for cell-cycle arrest, the tissue inhibitor of metalloproteinases 2 (TIMP2) and insulin-like growth-factor binding protein 7 (IGFBP7), have shown promising results in an acute kidney-injury setting and could be transposed to kidney transplantation [13-15]. Finally, serum lactate dehydrogenase (sLDH), a non-specific marker for cell injury has been little studied following kidney transplantation, despite the availability of a cheap test.

The aim of this study was to identify the prognostic performance of injury-associated urinary biomarkers and sLDH to predict DGF and subsequent 3-month persistent graft dysfunction in patients with a DCD KT. In order to assess the association between these markers and ischemia-reperfusion injuries, values were compared with those from patients with a LD KT ("gold standard") performed within the same period.

\section{Methods}

\section{$\underline{\text { Study design and population }}$}

This was a prospective, observational, single-center cohort study. Fifty-four consecutive patients receiving either LD KT or DCD KT between February 2014 and July 2016 in our center were included in this study. Exclusion criteria were patients aged $<18$ years and ABO and/or human leukocyte antigen (HLA) incompatible KTs. Six patients with LD KT had major graft dysfunction in the early post-transplant period (i.e. within less than three months posttransplant) secondary to complications: thus, they could no longer be considered as reference KT patients and their data were excluded (of the six: one died, two had graft-artery 
stenosis, one had acute kidney injury, one had graft rejection on day 11 post-transplant, and one had recurrence of nephropathy). The study was performed in accordance with the ethical standards laid down in the 2000 Declaration of Helsinki and the Declaration of Istanbul 2008. Each included participant signed an informed-consent form before enrollment. This study is an ancillary study to another that aims to identify the urinary proteomic profile of the accommodation phenomenon in the presence of donor-specific antibodies (DSAs) among KT recipients (Grenoble Institutional Review Board number 6705).

\section{$\underline{D C D K T}$}

All patients, except one, received a Maastricht II category graft; the exception was Maastricht III category [16]. Inclusion and exclusion of both donors and recipients followed the French Biomedicine Agency protocols [17]. Normothermic regional circulation was used in all cases. All kidneys were subsequently machine perfused $\left(\right.$ LifePort $^{\odot}$ Kidney Transporter 1.1, Organ Recovery Systems) and kidneys with end-perfusion resistive indices greater than 0.3 $\mathrm{mmHg} / \mathrm{mL} / \mathrm{min}$ were discarded [18]. No routine biopsy was performed on the graft before transplantation.

\section{Management of patients and follow-up}

In our center, standard immunosuppression consisted of induction treatment using anti-thymocyte globulin (DCD KT and LD KT) or basiliximab (in some LD KT), with a maintenance immunosuppressive regimen consisting of calcineurin inhibitors (tacrolimus) introduced at day 4, and mycophenolate mofetil and prednisone at day 0. During the first month following KT, a trough tacrolimus concentration of $8--12 \mu \mathrm{g} / \mathrm{L}$ and then $5--8 \mu \mathrm{g} / \mathrm{L}$ was targeted. 
After discharge of a patient, follow-up visits were scheduled at day 15, at 6 weeks, and at 3 months. A graft biopsy was systematically performed at 3 months to detect any subclinical acute rejection. All biopsies were scored according to the semi-quantitative 2013--2015 Banff classification [19]. Routine urine and serum biological monitoring was performed according to our clinical protocol.

\section{$\underline{\text { Data collection }}$}

Demographic data (patient gender, age, initial nephropathy, body-mass index, prior anti-HLA sensitization), KT characteristics (donor age and serum creatinine, cold-ischemia time, resistive indices when placing the kidney on a perfusion machine and at 30 minutes after perfusion on that machine, number of HLA mismatches), and patient evolution (dialysis requirement, presence of de novo DSA, biopsy results at 3 months, BK virus infection) were recorded.

Serum creatinine, sLDH, urinary creatinine, uNGAL and uNAG were measured at days 1 and 3 , and uNGAL and serum creatinine were assessed at day 7, at 6 weeks, and at 3 months. The initial protocol did not include urinary TIMP2 and IGFBP7, which were added after patient inclusion as this was considered to be a novel but promising biomarker [20]. Serum creatinine, $\mathrm{LDH}$, and urine creatinine analyses were performed on the sample day, whereas urine samples for the other markers were centrifuged at room temperature for $10 \mathrm{~min}$ at $2000 \mathrm{~g}$, then decanted, aliquoted, frozen, and stored at $-20^{\circ} \mathrm{C}$. uNGAL was measured using an ELISA test (Human NGAL ELISA kit 036CE, Bioporto Diagnostics, Hellerup, Denmark), uNAG was measured using a colorimetric test (10875406001 kit, Roche Life Science), and [TIMP2]·[IGFBP7] was measured using a sandwich immunoassay technique (NephroCheck ${ }^{\mathrm{TM}}$, Astute Medical, San Diego, CA, USA). uNAG and uNGAL are presented as a ratio, i.e., they were divided by the urinary creatinine value. 


\section{$\underline{\text { Outcomes }}$}

The primary outcome was the occurrence of DGF, defined as the requirement of at least one dialysis session within the first week post-transplantation.

Secondary outcomes were: persistent kidney dysfunction at 3 months in DCD KT patients, defined as an estimated glomerular filtration rate $<45 \mathrm{~mL} / \mathrm{min} / 1.73 \mathrm{~m}^{2}$ (Chronic Kidney Disease - Epidemiology Collaboration (CKD-EPI) equation [21]) or the need for dialysis at 3 months. Sub-clinical rejection was assessed from a biopsy performed at 3 months post-transplantation.

\section{$\underline{\text { Missing data }}$}

Patients that did not have complete uNAG, uNGAL, creatinine or sLDH values at day 1 or 3 were excluded from the analysis (i.e., six DCD KTs and one LD KT). It was decided to conserve the data from patients when [TIMP2].[IGFBP7] measurement was absent because this dosage was added afterwards. A complete case analysis was performed for each outcome; imputation was not performed. It was hypothesized that missing data followed a random pattern.

\section{$\underline{\text { Statistics }}$}

Quantitative variables are described as their medians and interquartile ranges and were compared using the Wilcoxon-rank or Kruskal--Wallis test, as appropriate. Qualitative variables are presented as their frequencies and percentages and were compared using Fisher's exact test (because of the small population size).

Spearman's correlation coefficients between urine and serum biomarkers and transplantation characteristics (i.e., cold-ischemia time, resistive index, donor age, creatinine value at graft removal) were assessed. A strong correlation was defined as a coefficient of $>0.5$. 
Receiver operating characteristics (ROC) analysis was performed to assess uNAG, uNGAL, [TIMP2]-[IGFBP7], and sLDH on the day-1 respective predictive performances of the primary outcome. No logistic regression for multivariate analyses was performed due to the small population size. A $p$-value of 0.05 was considered to be statistically significant. All analyses were conducted using R software, version 3.3.1.

\section{Results}

\section{Patients' characteristics}

Of the 54 patients screened, 41 were included in the analysis: $15(36.6 \%)$ DCD KTs and 26 (63.4\%) LD KTs (Figure 1). Nine (60.0\%) of the DCD KT patients experienced DGF.

The patients' baseline characteristics are presented in Table 1. Median age was 54.0 years [range: 49.0-58.5] and 36.5 years [range: 30.0-54.25] for DCD KT and LD KT patients, respectively $(p=0.02)$. Concerning the donors' characteristics, DCDs were slightly younger without reaching statistical difference (46.0 years [range: 38.0-48.0] vs. 50.0 years [range: 39.5-55.0]) $(p=0.07)$ and had higher creatinine values at graft removal $(111 \mu \mathrm{mol} / \mathrm{L}$ [range: 83.5-134.5] vs. $74.5 \mu \mathrm{mol} / \mathrm{L}$ [range: $64.5-79.75], p=<0.01)$.

There was no statistically significant difference between DCD KT patients with or without DGF regarding donor age, creatinine value at graft removal, cold-ischemia time, or number of HLA mismatches, including DQ mismatches (data not shown).

\section{Primary endpoint: delayed graft function}

A total of 34 patients with complete data were included in the analysis, including 12 with DCD KT, six of whom had DGF, with a median of 16 days between transplantation procedure and the last dialysis session. 
Among the biomarkers measured at day 1, there was a statistically significant difference between LD and DCD KTs for sLDH, serum creatinine, uNAG, and uNGAL (sLDH: 221 IU/L [184.5; 247] vs. 531 IU/L [310.2; 828], $p<0.01$; serum creatinine: $358.5 \mu \mathrm{mol} / \mathrm{L}$ [243.5; 430.2] vs. $562 \mu \mathrm{mol} / \mathrm{L}[513.5 ; 710.5], p<0.01$; uNAG: $0.52 \mathrm{IU} / \mathrm{mmol}[0.38 ; 0.9]$ vs. 0.96 [0.69; 2.6], $p=0.02$; uNGAL: $45.62 \mu \mathrm{g} / \mathrm{mmol}[15.14 ; 103.24] v s .126 .58 \mu \mathrm{g} / \mathrm{mmol}[52.38$; 285.36], $\mathrm{p}=0.01$ ), and between DCD KTs with DGF vs. DCD KTs without DGF (sLDH: 954 IU/L [633.8; 1487.2] vs. 310.5 IU/L [289.2; 416.5], $p=0.04$; serum creatinine: $742 \mu \mathrm{mol} / 1$ [634.8; 1048.8] vs. $506 \mu \mathrm{mol} / 1$ [470; 541.2], $p<0.01$; uNAG: $3.30 \mathrm{IU} / \mathrm{mmol}[1.37 ; 6.10] v s$. $0.68 \mathrm{IU} / \mathrm{mmol}[0.42 ; 0.77], p<0.01 ;$ uNGAL: $298.9 \mu \mathrm{g} / \mathrm{mmol}$ [248; 442.75] vs. 59.87 $\mu \mathrm{g} / \mathrm{mmol}[52.13 ; 108.27], p=0.04)$ (Figure 2).

Similarly, there was a statistically significant difference between DCD KTs without DGF compared to LD KTs for sLDH and serum creatinine (sLDH: 310.5 IU/L [289.2; 416.5] vs. $221 \mathrm{IU} / \mathrm{L}[184.5 ; 247], p<0.01$; serum creatinine: $506 \mu \mathrm{mol} / \mathrm{L}[470 ; 541.2] v s .385 .5 \mu \mathrm{mol} / \mathrm{L}$ [243.5; 430.2], $p=0.01$ ), whereas there was no difference for UNAG and uNGAL (uNAG: $0.68 \mathrm{IU} / \mathrm{mmol}[0.42 ; 0.77]$ vs. $0.52 \mathrm{IU} / \mathrm{mmol}[0.38 ; 0.90], p=0.76$; uNGAL: $59.87 \mu \mathrm{g} / \mathrm{mmol}$ $[52.13 ; 108.27]$ vs. $45.62 \mu \mathrm{g} / \mathrm{mmol}[15.14 ; 103.24], p=0.53)$.

For patients with data available for [TIMP2].[IGFBP7] ( $n=32$, including four DCD KT patients with DGF), there was a statistically significant difference between LD KTs and DCD KTs $\left(0.07(\mathrm{ng} / \mathrm{mL})^{2} / 1000[0.05 ; 0.14]\right.$ vs. $\left.0.31(\mathrm{ng} / \mathrm{mL})^{2} / 1000[0.13 ; 0.7], p=0.01\right)$ and between DCD KTs with DGF and DCD KTs without DGF (1.56 (ng/mL)²/1000 [0.70; 2.61] vs. $\left.0.17(\mathrm{ng} / \mathrm{mL})^{2} / 1000[0.07 ; 0.29], p=0.01\right)$. In contrast, the difference between DCD KTs without DGF and LD KTs was not statistically significant $\left(0.17(\mathrm{ng} / \mathrm{mL})^{2} / 1000\right.$ [0.07: 0.29] vs. $\left.0.07(\mathrm{ng} / \mathrm{mL})^{2} / 1000[0.05 ; 0.14], p=0.23\right)$. When performing ROC analysis on the 10 DCD KTs, the biomarkers with the highest area under the curve (AUC) were UNGAL and [TIMP2].[IGFBP7] with a value of 1 . The AUC for sLDH was 0.92 (95\%CI: 0.73-1.0) and 
was 0.96 (95\%CI: 0.84-1) for uNAG (Figure 3). A comparison between AUCs was not performed due to the small population size.

Of the transplantation characteristics $(n=12)$, only 30-minute resistive index was significantly higher for DCD KTs with DGF compared to DCD KTs without DGF $(0.26 \mathrm{mmHg} / \mathrm{mL} / \mathrm{min}$ $[0.20 ; 0.32] v s .0 .14 \mathrm{mmHg} / \mathrm{mL} / \mathrm{min}[0.12 ; 0.16], p=0.05)$. It is notable that the resistive index, when the kidney was placed on the perfusion machine, did not differ between groups $(0.43 \mathrm{mmHg} / \mathrm{mL} / \mathrm{min}[0.34 ; 0.51]$ vs. $0.34 \mathrm{mmHg} / \mathrm{mL} / \mathrm{min}[0.31 ; 0.35], p=0.38$. When studying correlations between biomarkers and transplantation characteristics $(n=10)$, a strong correlation for all the biomarkers (uNGAL, uNAG, sLDH and [TIMP2].[IGFBP7]) was only found with the 30-minute resistive index ( $\mathrm{rho}=0.84,0.62,0.54$, and 0.79 , respectively).

\section{Graft function at 3 months}

Of the 12 DCD KT patients with complete day-3 values, three suffered from persistent graft dysfunction at 3 months, without dialysis dependency. Median creatinine clearance among DGF DCD KT was $49 \mathrm{~mL} / \mathrm{min} / 1.73 \mathrm{~m}^{2}[42 ; 65]$ and $65 \mathrm{ml} / \mathrm{min} / 1.73 \mathrm{~m}^{2}[62 ; 66]$ among DCD Kts without DGF $(p=0.22)$. Day 3 uNAG, uNGAL and [TIMP2].[IGFBP7] were not associated with the 3-month graft outcomes ( $p=0.27,0.6,0.15$, respectively), whereas sLDH was associated $(p=0.02)$. When considering median day-3 sLDH value (400 IU/L), median creatinine clearance was $54.5 \mathrm{ml} / \mathrm{min} / 1.73 \mathrm{~m}^{2}$ [41; 68.75] in patients with higher sLDH values vs. $61 \mathrm{ml} / \mathrm{min} / 1.73 \mathrm{~m}^{2}[60-65]$ in patients with lower values. Day-3 biomarker values appeared to be related to short-term graft outcomes and notably the occurrence of DGF (Figure 4). Similarly, 30-minute resistive index did not differ between the two groups ( $p=$ 0.08). For the 12 patients with complete day-1 values (i.e., two persistent dysfunctions), none of the biomarkers was statistically associated with 3-month persistent dysfunction.

\section{Biopsy-proven graft rejection at 3 months}


Of the 41 patients included, 36 underwent a biopsy at 3 months. Of these, two DCD KTs $(15.38 \%)$ and four LD KTs $(17.39 \%)$ experienced subclinical graft rejection $(p=1.00)$. Of the 31 patients with complete day-1 values, five had a subclinical graft rejection. Neither the overall population nor the patient subgroups (i.e., DCD or LD KT status), based on uNAG, sLDH, uNGAL, or [TIMP2].[IGFBP7] values on day 1, was associated with subsequent subclinical graft rejection. Results were similar for the 32 patients with complete day-3 values.

\section{$\underline{\text { uNGAL kinetics }}$}

The kinetics for uNGAL over the first 3 months post-transplantation are presented in Figure 5. Although uNGAL was high in both groups on day 1, it then decreased substantially by day 3 in the LD KT group. At 6 weeks and 3 months, uNGAL values were low in both groups.

\section{Discussion}

This is the first study to extensively assess the prognostic performance of several urinary biomarkers of tubular injury in addition to serum LDH to predict short- and mid-term graft outcomes in DCD KT patients using LD KT patients as the "gold standard". uNGAL, uNAG, [TIMP2].[IGFBP7] and sLDH showed promising results to predict DGF, defined as requiring dialysis in the first week post-transplantation. Interestingly, the 30-minute resistive index on the perfusion machine appeared to be associated with DGF. Measured markers were poorly associated with the 3-month outcomes.

Traditionally, graft dysfunction has been diagnosed based on increased serum creatinine, in association with urine output, despite its obvious limitations. Increased serum creatinine is only evident $24--48 \mathrm{~h}$ after kidney injury, which is the time required to reach a new steady state between constant creatinine generation and its elimination via the new glomerular- 
filtration rate [9]. Hence, although it remains the reference method to assess acute changes in renal function [22], serum creatinine cannot be considered as a "gold standard" [23]. In the setting of kidney transplantation, diagnosis of DGF requires a kinetic approach rather than a unique measurement, which leads, in most cases, to a 48-hour delay.

In order to predict DGF, uNGAL values on day 1 were analyzed. In previous studies, uNGAL values appeared to reach a maximum at 24--48 hours after kidney transplantation $[24,25]$, therefore, the timing used to measure it in this study seems appropriate. Moreover, we considered that values measured at 48--72 hours post-surgery were of little benefit because they were mostly performed after the first dialysis session, thus, providing no further information other than serum-creatinine level. In our study, uNGAL measured at day 1 in DCD KT patients seemed to both sensitively and specifically predict DGF. These results are in agreement with previous studies conducted on LD and DBD KT patients [11, 24, 25]. Based on the current results, uNGAL dosage may reflect lesion severity. [TIMP2].[IGFBP7] is associated with cell cycle arrest of tubular cells in G1 stage when an injury occurs, a mechanism that could be protective [26]. It has emerged in recent years as the most promising acute kidney-injury biomarker [20, 27] in various settings, without being modified by patient comorbidities [28]. Studies on its association with kidney transplantation are few [13-15] and no study has been conducted specifically in DCD KTs. In this current study, it has been confirmed that [TIMP2].[IGFBP7] could be a useful biomarker in this context, allowing the early identification of patients at risk for DGF. Similarly, the day-1 sLDH, showed an ability to predict DGF and thus merits further study, considering that it is a routine, convenient and very cheap measurement and is easy to implement in every-day practice. Finally, in agreement with several studies indicating the potential of NAG to predict short- and long-term graft outcomes [12], the results presented for UNAG also appear interesting in this setting. It should be noted that the perfect uNGAL and [TIMP2].[IGFBP7] AUCs in the current study is 
probably linked to the small population size, thus not enabling direct comparison with the sLDH and uNAG AUCs.

Perfusion machines have improved the short-term outcomes after DCD KT. However, the longer term benefits are uncertain [29, 30], reflecting the severity of ischemic injuries inherent in this type of donor. Currently, resistive index on the perfusion machine have been used to assess graft viability, in particular at the end of perfusion [31]. A high index indicates grafts that have a high risk of primary non-function [32] and has been used as an indicator for decision making as to whether to discard a graft [33]. Interestingly, in our study, the 30-minute resistive index on the perfusion machine was marginally associated with DGF in DCD KT patients.

Other baseline characteristics (donor and recipient ages, donor serum creatinine, cold-ischemia time) $[34,35]$, which are classically associated with DGF, were not significant in this study. This could be due to the homogeneity of donor pre-conditioning, graft conditioning, or the surgery, as well as to the monocentric nature of our study. Furthermore, kidney grafts were only sourced from a single center in this study.

Neither uNGAL, uNAG, [TIMP2].[IGFBP7] nor the 30-minute resistive index were predictive of 3-month persisting dysfunction. It is notable that sLDH was associated with the 3-month outcome. However, this single significant result was probably due to multiple comparison and should be interpreted with caution. These findings are in contrast with previous studies on other kidney-transplant populations $[11,24]$. The levels of these markers at days 1 and 3 were strongly associated with DGF in the current study. In previous studies, the DGF impact on DCD KT patients' long-term outcomes appeared to be moderate compared to other types of transplantation [36, 37], however, this remains controversial [7]. In our cohort, 3-month persistent dysfunction in DCD KT patients appears to be linked to subsequent events rather than to transplantation characteristics or DGF. The lack of a 
predictive performance of our marker could confirm the lower impact of DGF on long-term graft outcomes after DCD KT, which is in agreement with DCD KT satisfying outcomes despite a higher incidence of DGF [1]. A possible explanation could be milder up-regulation of inflammatory and injury genes in comparison to DBD [38]. We also acknowledge that the small size of our population, and thus the low incidence of events of interest, may have prevented us obtaining a significant result.

The kinetics of uNGAL in the first 3 months post-transplantation was of interest. On day 1 , uNGAL was elevated in patients undergoing LD KT, suggesting the existence of tubular injury, even for this type of transplantation. However, the earlier decrease in UNGAL in LD KT could be explained by less extensive or less severe lesions compared to those encountered with DCD KT. At both 6 weeks and 3 months, the uNGAL level indicated the disappearance of tubular injuries in both groups.

This study has several strengths. Firstly, only one previous study has studied biomarker performance specifically within a DCD KT population but was limited to serum NGAL [39]. Based on our results, a score associating uNGAL, sLDH, uNAG, [TIMP2].[IGFBP7], and possibly the 30-minute resistive index could help identify patients at higher risk for DGF. Specific therapeutic measures could then be implemented at an early stage, similar to the QPI1002 study (Quark Pharmaceuticals), where the anti-apoptotic siRNA targeting p53 gene was investigated [40].

Our study has some limitations. Firstly, the small population size may have prevented definitive conclusions to be drawn. However, it should be noted that DCD KT is relatively rare in France (62 cases reported in 2015). Secondly, sample collection could have been better standardized during the early post-transplantation period. The delay between transplantation and sampling time on day 1 varied between patients and, consequently, these comparisons 
may not be viable. However, the time before sampling only ranged between 18 and 33 hours, a time difference which seems unlikely to have influenced the results.

In conclusion, in the DCD KT population, clinical (30-minute resistive index on a perfusion machine) and biological markers (uNGAL, uNAG, [TIMP2].[IGFBP7] and sLDH) could provide a predictive score for DGF: they could thus identify patients at risk and allow modification of their management accordingly. In particular, due to its availability and low cost, sLDH could be recommended as a routine measurement in transplant centers. Our findings should be investigated further in a larger cohort. 


\section{$\underline{\text { References }}$}

1. Summers DM, Watson CJ, Pettigrew GJ, Johnson RJ, Collett D, Neuberger JM, et al. Kidney donation after circulatory death (CDD): state of the art. Kidney Int. 2015 Aug;88(2):241-9.

2. Snoeijs MG, Schaubel DE, Hene R, Hoitsma AJ, Idu MM, Ijzermans JN, et al. Kidneys from donors after cardiac death provide survival benefit. J Am Soc Nephrol. 2010 Jun;21(6):1015-21.

3. Abboud I, Viglietti D, Antoine C, Gaudez F, Meria P, Tariel E, et al. Preliminary results of transplantation with kidneys donated after cardiocirculatory determination of death: a French single-centre experience. Nephrol Dial Transplant. 2012 Jun;27(6):2583-7.

4. Mallon DH, Summers DM, Bradley JA, Pettigrew GJ. Defining delayed graft function after renal transplantation: simplest is best. Transplantation. 2013 Nov 27;96(10):885-9.

5. Wu WK, Famure O, Li Y, Kim SJ. Delayed graft function and the risk of acute rejection in the modern era of kidney transplantation. Kidney Int. 2015 Oct;88(4):851-8.

6. Giral-Classe M, Hourmant M, Cantarovich D, Dantal J, Blancho G, Daguin P, et al. Delayed graft function of more than six days strongly decreases long-term survival of transplanted kidneys. Kidney Int. 1998 Sep;54(3):972-8.

7. Brook NR, White SA, Waller JR, Veitch PS, Nicholson ML. Non-heart beating donor kidneys with delayed graft function have superior graft survival compared with conventional heart-beating donor kidneys that develop delayed graft function. Am J Transplant. 2003 May;3(5):614-8.

8. Salvadori M, Rosso G, Bertoni E. Update on ischemia-reperfusion injury in kidney transplantation: Pathogenesis and treatment. World J Transplant. 2015 Jun 24;5(2):52-67.

9. Ronco C, Kellum JA, Haase M. Subclinical AKI is still AKI. Crit Care. $2012 ; 16(3): 313$ 
10. Halawa A. The early diagnosis of acute renal graft dysfunction: a challenge we face. The role of novel biomarkers. Ann Transplant. 2011 Jan-Mar;16(1):90-8.

11. Hall IE, Yarlagadda SG, Coca SG, Wang Z, Doshi M, Devarajan P, et al. IL-18 and urinary NGAL predict dialysis and graft recovery after kidney transplantation. J Am Soc Nephrol. 2010 Jan;21(1):189-97.

12. Kwiatkowska E, Domanski L, Bober J, Kloda K, Safranow K, Szymanska-Pasternak J, et al. N-acetyl-beta-glucosaminidase urine activity as a marker of early proximal tubule damage and a predictor of the long-term function of the transplanted kidneys. Acta Biochim Pol. 2014;61(2):275-80.

13. Pajenda S, Ilhan-Mutlu A, Preusser M, Roka S, Druml W, Wagner L. NephroCheck data compared to serum creatinine in various clinical settings. BMC Nephrol. 2015 Dec 09;16:206.

14. Pianta TJ, Peake PW, Pickering JW, Kelleher M, Buckley NA, Endre ZH. Evaluation of biomarkers of cell cycle arrest and inflammation in prediction of dialysis or recovery after kidney transplantation. Transpl Int. 2015 Dec;28(12):1392-404.

15. Yang J, Lim SY, Kim MG, Jung CW, Cho WY, Jo SK. Urinary Tissue Inhibitor of Metalloproteinase and Insulin-like Growth Factor-7 as Early Biomarkers of Delayed Graft Function After Kidney Transplantation. Transplant Proc. 2017 Nov;49(9):2050-4.

16. Kootstra G, Daemen JH, Oomen AP. Categories of non-heart-beating donors. Transplant Proc. 1995 Oct;27(5):2893-4.

17. https://urgences-serveur.fr/IMG/pdf/DVprotocole_V12_avril_2007.pdf..Conditions à respecter pour réaliser des prélèvements de rein sur des donneurs à coeur arrêté dans un établissement de santé autorisé aux prélèvements d'organes. Agence de la Biomédecine Avril 2007.18. Billault C, Para J, Barrou B. Comment mettre un greffon rénal sur machine de perfusion : expérience avec la machine LifePort ${ }^{\circledR}$ Kidney Transporter 1.0. Progrès en 
Urologie FMC. 2013;23(3):F70-F76.19. Haas M, Sis B, Racusen LC, Solez K, Glotz D, Colvin RB, et al. Banff 2013 meeting report: inclusion of c4d-negative antibody-mediated rejection and antibody-associated arterial lesions. Am J Transplant. 2014 Feb;14(2):272-83.

20. Kashani K, Al-Khafaji A, Ardiles T, Artigas A, Bagshaw SM, Bell M, et al. Discovery and validation of cell cycle arrest biomarkers in human acute kidney injury. Crit Care. 2013 Feb 6;17(1):R25.

21. Levey AS, Stevens LA, Schmid CH, Zhang YL, Castro AF, 3rd, Feldman HI, et al. A new equation to estimate glomerular filtration rate. Ann Intern Med. 2009 May 5;150(9):60412.

22. [No authors listed]. Section 2: AKI Definition. Kidney Int Suppl (2011). 2012;2(1):1936. DOI: 10.1038/kisup.2011.3223. Solomon R, Segal A. Defining acute kidney injury: what is the most appropriate metric? Nat Clin Pract Nephrol. 2008 Apr;4(4):208-15.

24. Fonseca I, Oliveira JC, Almeida M, Cruz M, Malho A, Martins LS, et al. Neutrophil gelatinase-associated lipocalin in kidney transplantation is an early marker of graft dysfunction and is associated with one-year renal function. J Transplant. 2013;2013:650123.

25. Cui LY, Zhu X, Yang S, Zhou JS, Zhang HX, Liu L, et al. Prognostic Value of Levels of Urine Neutrophil Gelatinase-associated Lipocalin and Interleukin-18 in Patients With Delayed Graft Function After Kidney Transplantation. Transplant Proc. 2015 Dec;47(10):2846-51.

26. Kellum JA, Chawla LS. Cell-cycle arrest and acute kidney injury: the light and the dark sides. Nephrol Dial Transplant. 2016 Jan;31(1):16-22.

27. Bihorac A, Chawla LS, Shaw AD, Al-Khafaji A, Davison DL, Demuth GE, et al. Validation of cell-cycle arrest biomarkers for acute kidney injury using clinical adjudication. Am J Respir Crit Care Med. 2014 Apr 15;189(8):932-9. 
28. Heung M, Ortega LM, Chawla LS, Wunderink RG, Self WH, Koyner JL, et al. Common chronic conditions do not affect performance of cell cycle arrest biomarkers for risk stratification of acute kidney injury. Nephrol Dial Transplant. 2016 Oct;31(10):1633-40.

29. Deng R, Gu G, Wang D, Tai Q, Wu L, Ju W, et al. Machine perfusion versus cold storage of kidneys derived from donation after cardiac death: a meta-analysis. PLoS One. 2013;8(3):e56368.

30. Lodhi SA, Lamb KE, Uddin I, Meier-Kriesche HU. Pulsatile pump decreases risk of delayed graft function in kidneys donated after cardiac death. Am J Transplant. 2012 Oct;12(10):2774-80.

31. Jochmans I, Moers C, Smits JM, Leuvenink HG, Treckmann J, Paul A, et al. The prognostic value of renal resistance during hypothermic machine perfusion of deceased donor kidneys. Am J Transplant. 2011 Oct;11(10):2214-20.

32. Light J. Viability testing in the non-heart-beating donor. Transplant Proc. 2000 Feb;32(1):179-81.

33. Nyberg SL, Baskin-Bey ES, Kremers W, Prieto M, Henry ML, Stegall MD. Improving the prediction of donor kidney quality: deceased donor score and resistive indices. Transplantation. 2005 Oct 15;80(7):925-9.

34. Chapal M, Le Borgne F, Legendre C, Kreis H, Mourad G, Garrigue V, et al. A useful scoring system for the prediction and management of delayed graft function following kidney transplantation from cadaveric donors. Kidney Int. 2014 Dec;86(6):1130-9.

35. Siedlecki A, Irish W, Brennan DC. Delayed graft function in the kidney transplant. Am J Transplant. 2011 Nov;11(11):2279-96.

36. Singh RP, Farney AC, Rogers J, Zuckerman J, Reeves-Daniel A, Hartmann E, et al. Kidney transplantation from donation after cardiac death donors: lack of impact of delayed graft function on post-transplant outcomes. Clin Transplant. 2011 Mar-Apr;25(2):255-64. 
37. Molina M, Guerrero-Ramos F, Fernandez-Ruiz M, Gonzalez E, Cabrera J, Morales E, et al. Kidney transplantation from uncontrolled donation after circulatory death donors maintained by nECMO has long-term outcomes comparable to standard criteria donation after brain death. Am J Transplant. 2018 Jun 27.

38. Saat TC, Susa D, Roest HP, Kok NF, van den Engel S, Ijzermans JN, et al. A comparison of inflammatory, cytoprotective and injury gene expression profiles in kidneys from brain death and cardiac death donors. Transplantation. 2014 Jul 15;98(1):15-21.

39. Kusaka M, Kuroyanagi Y, Mori T, Nagaoka K, Sasaki H, Maruyama T, et al. Serum neutrophil gelatinase-associated lipocalin as a predictor of organ recovery from delayed graft function after kidney transplantation from donors after cardiac death. Cell Transplant. 2008;17(1-2):129-34.

40. Imamura R, Isaka Y, Sandoval RM, Ori A, Adamsky S, Feinstein E, et al. Intravital two-photon microscopy assessment of renal protection efficacy of siRNA for p53 in experimental rat kidney transplantation models. Cell Transplant. 2010;19(12):1659-70. 
Table 1: Initial characteristics of the overall population $(n=41)$ :

\section{CDD KTs without $\quad$ DGF CDD KTs $(n=9) \quad$ LD KTs $(n=26) \quad p$-value \\ DGF $(n=6)$}

\begin{tabular}{|c|c|c|c|c|}
\hline \multicolumn{5}{|c|}{ Recipient: donor and transplantation characteristics } \\
\hline \multicolumn{5}{|l|}{ Recipient } \\
\hline Age (years) & $56[50.25 ; 58.75]$ & $53[49 ; 55]$ & $36.5[30 ; 54.25]$ & 0.05 \\
\hline Gender (male) & $6(100)$ & $9(100)$ & $18(60.23)$ & 0.06 \\
\hline BMI & $26.86[24.3 ; 28.02]$ & $24.84[22.74 ; 26.23]$ & $23.08[21.23 ; 26.12]$ & 0.32 \\
\hline Initial nephropathy & & & & 0.56 \\
\hline
\end{tabular}

\begin{tabular}{|c|c|c|c|c|}
\hline Uropathy & $1(16.66)$ & 0 & $4(15.38)$ & \\
\hline Polycystic kidney & $1(16.66)$ & $4(44.44)$ & $6(23.08)$ & \\
\hline Glomerulopathy & $2(33.33)$ & $2(22.22)$ & $7(26.92)$ & \\
\hline Metabolic & $2(33.33)$ & $1(11.11)$ & $2(7.69)$ & \\
\hline Other & 0 & $2(22.22)$ & $7(26.92)$ & \\
\hline HLA sensitization & 0 & 0 & $5(19.23)$ & 0.29 \\
\hline \multicolumn{5}{|l|}{ Donor } \\
\hline Donor age (years) & $47[40.25 ; 48.5]$ & $43[38 ; 46]$ & $50[39.5 ; 55.0]$ & 0.17 \\
\hline $\begin{array}{r}\text { Serum creatinine at } \\
\text { graft removal } \\
(\mu \mathrm{mol} / \mathrm{L})\end{array}$ & $94.5[82.25 ; 139.75]$ & $118[87 ; 128]$ & $74.5[64.5 ; 79.75]$ & $<0.01$ \\
\hline \multicolumn{5}{|l|}{ Transplantation } \\
\hline $\begin{array}{l}\text { Cold ischemia time } \\
\qquad(\mathrm{min})\end{array}$ & $660.5[566.2 ; 918.2]$ & $797[617 ; 824]$ & $80[75.25 ; 95.5]$ & $<0.01$ \\
\hline
\end{tabular}




\begin{tabular}{|c|c|c|c|c|}
\hline $\begin{array}{r}\text { Number of HLA } \\
\text { mismatches }\end{array}$ & $5[4 ; 7.5]$ & $5[4 ; 6]$ & $3.5[2 ; 5]$ & 0.08 \\
\hline $\begin{array}{r}\text { Number of HLA-DQ } \\
\text { mismatches }\end{array}$ & $1[1 ; 1.75]$ & $1[1 ; 1]$ & $1[0 ; 1]$ & 0.06 \\
\hline 30-min resistive index & $0.14[0.12 ; 0.16]$ & $0.25[0.11 ; 0.28]$ & & 0.19 \\
\hline \multicolumn{5}{|c|}{ Biomarker characteristics } \\
\hline $\begin{array}{r}\text { uNAG day } 1 \\
(\text { IU/mmol) }\end{array}$ & $0.68[0.42 ; 0.77]$ & $1.89[1.42 ; 5.64]^{\mathrm{a}}$ & $0.52[0.38 ; 0.94]^{\mathrm{a}}$ & $<0.01$ \\
\hline $\begin{array}{r}\text { uNGAL day } 1 \\
(\mu \mathrm{g} / \mathrm{mmol})\end{array}$ & $\begin{array}{r}59.87[52.13 ; \\
108.27]\end{array}$ & $298.9[248 ; 442.75]^{\mathrm{b}}$ & $46.68[15.33 ; 100.95]^{b}$ & 0.01 \\
\hline sLDH day-1 (IU/L) & $310.5[289.2 ; 416.5]$ & $954[633.8 ; 1487.2]^{\mathrm{b}}$ & $220[185 ; 245]^{b}$ & $<0.01$ \\
\hline $\begin{array}{r}\text { Serum creatinine day } \\
1(\mu \mathrm{mol} / \mathrm{L})\end{array}$ & \multicolumn{4}{|c|}{$1(\mu \mathrm{mol} / \mathrm{L})$} \\
\hline $\begin{array}{r}\text { [TIMP2].[IGFBP7] } \\
\left((\mathrm{ng} / \mathrm{mL})^{2} / 1000\right)\end{array}$ & $0.17[0.07 ; 0.29]$ & $0.72[0.65 ; 2.39]^{\mathrm{c}}$ & $0.07[0.05 ; 0.13]^{\mathrm{a}}$ & 0.01 \\
\hline \multicolumn{5}{|l|}{ Outcome } \\
\hline $\begin{array}{r}\text { 3-month persistent } \\
\text { dysfunction }\end{array}$ & $1(16.66)$ & $3(33.33)$ & $1(3.85)$ & 0.04 \\
\hline
\end{tabular}

Biopsy results

\begin{tabular}{rccc}
\hline Normal & $3(50.0)$ & $4(44.44)$ & $11(42.3)$ \\
\hline Reject & $2(33.33)$ & $0(0)$ & $4(15.38)$ \\
\hline Other & $0(0)$ & $4(44.44)$ & $8(30.77)$ \\
\hline No biopsy available & $1(16.66)$ & $1(11.11)$ & $3(11.54)$ \\
\hline BK virus at 3-month & & & 0.30
\end{tabular}




\begin{tabular}{|c|c|c|c|c|}
\hline Decoy cells & $2(33.33)$ & $2(22.22)$ & $4(15.38)$ & \\
\hline Serum PCR & 0 & $1(11.11)$ & 0 & \\
\hline $\begin{array}{l}\text { De-novo DSA at 3- } \\
\text { month }\end{array}$ & 0 & 0 & $1(3.85)$ & 1 \\
\hline
\end{tabular}

$\overline{\text { Quantitative variables are presented as medians (interquartile ranges) and qualitative variable }}$ as frequencies (corresponding percentages).

Abbreviations: CDD, donor after cardiac death; KT, kidney transplantation; DGF, delayed graft function; LD, living donor; BMI, body-mass Index; HLA, Human leukocyte antigen; uNAG, urinary N acetyl $\beta$-D glucosaminidase; uNGAL, urinary neutrophil gelatinaseassociated lipocalin; sLDH, serum lactate dehydrogenase; [TIMP2].[IGFBP7], [tissue inhibitor of metalloproteinases 2].[ insulin-like growth factor-binding protein 7]; PCR, polymerase chain reaction; DSA, donor-specific antibody

a 2 missing values

b 3 missing values

c 4 missing values 


\section{Figures}

\section{Figure 1: Flow chart}

Abbreviations: CDD, donor after cardiac death; KT, kidney transplantation; LD, living donor; DGF, delayed graft function

Figure 2: Urinary NGAL, NAG, [TIMP2].[IGFBP7] and serum LDH on day 1 posttransplantation according to donor type

Abbreviations: CDD, donor after cardiac death; DGF, delayed graft function; LD, living donor; NAG, N acetyl $\beta$-D glucosaminidase; NGAL, neutrophil gelatinase-associated lipocalin; [TIMP2].[IGFBP7], [tissue inhibitor of metalloproteinases 2].[ insulin-like growth factor-binding protein 7]; LDH, lactate dehydrogenase

Figure 3: ROC curves of urinary NGAL, NAG, [TIMP2].[IGFBP7] and serum LDH at day 1, and prediction of DGF after CDD kidney transplantation Abbreviations: ROC, receiver operating characteristics; NAG, N acetyl $\beta$-D glucosaminidase; NGAL, neutrophil gelatinase-associated lipocalin; [TIMP2].[IGFBP7], [tissue inhibitor of metalloproteinases 2].[ insulin-like growth factor-binding protein 7]; LDH, lactate dehydrogenase; DGF, delayed graft function; CDD, donor after cardiac death.

Figure 4: Urinary NGAL, NAG, [TIMP2].[IGFBP7] and serum LDH evolution from day 1 to day 3 post transplantation in CDD KT patients

Patients with DGF are indicated in light-grey; dark-grey indicates absence of DGF 
Abbreviations: NGAL, neutrophil gelatinase-associated lipocalin; NAG, N acetyl $\beta-D$

glucosaminidase; CCAM, cell-cycle arrest markers; LDH, lactate dehydrogenase; CDD, donor after cardiac death; KT, kidney transplantation

Figure 5: Urinary NGAL kinetics over the first 3 months post-transplantation, presented as the NGAL median value for $\mathrm{LD}$ and CDD KT patients at each time point.

Abbreviations: NGAL, neutrophil gelatinase-associated lipocalin; CDD, donor after cardiac death; LD, living donor; KT, kidney transplantation 


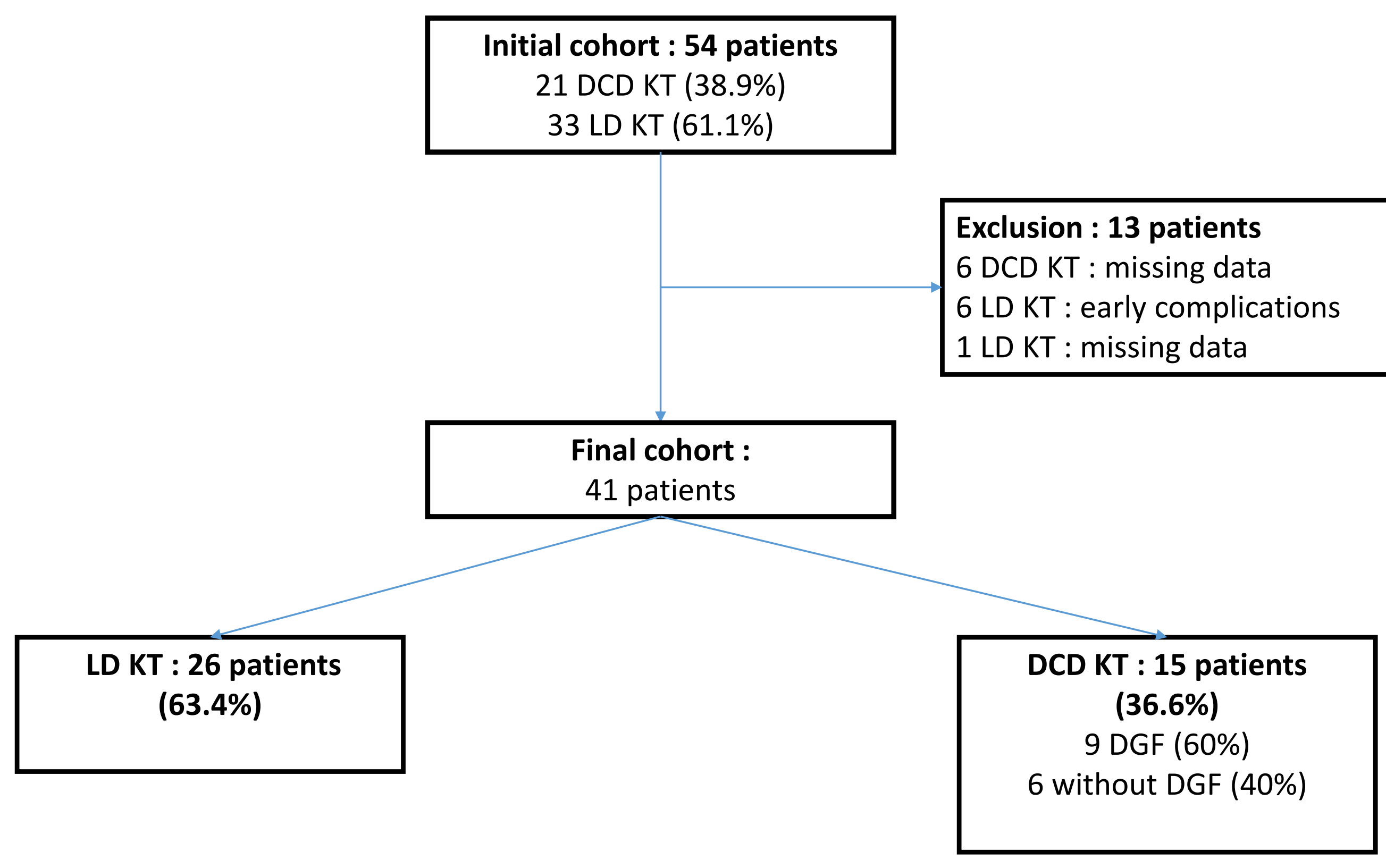



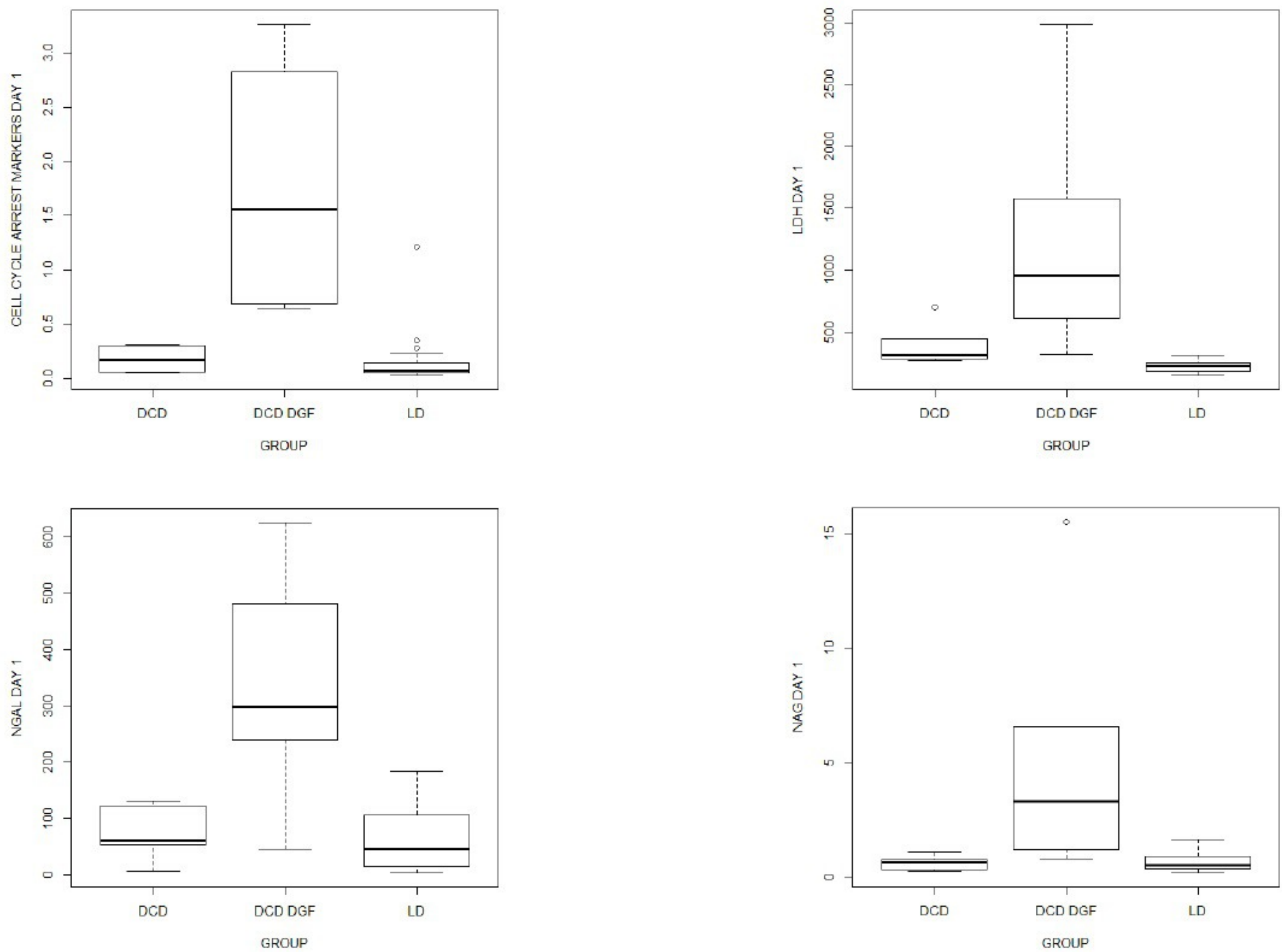


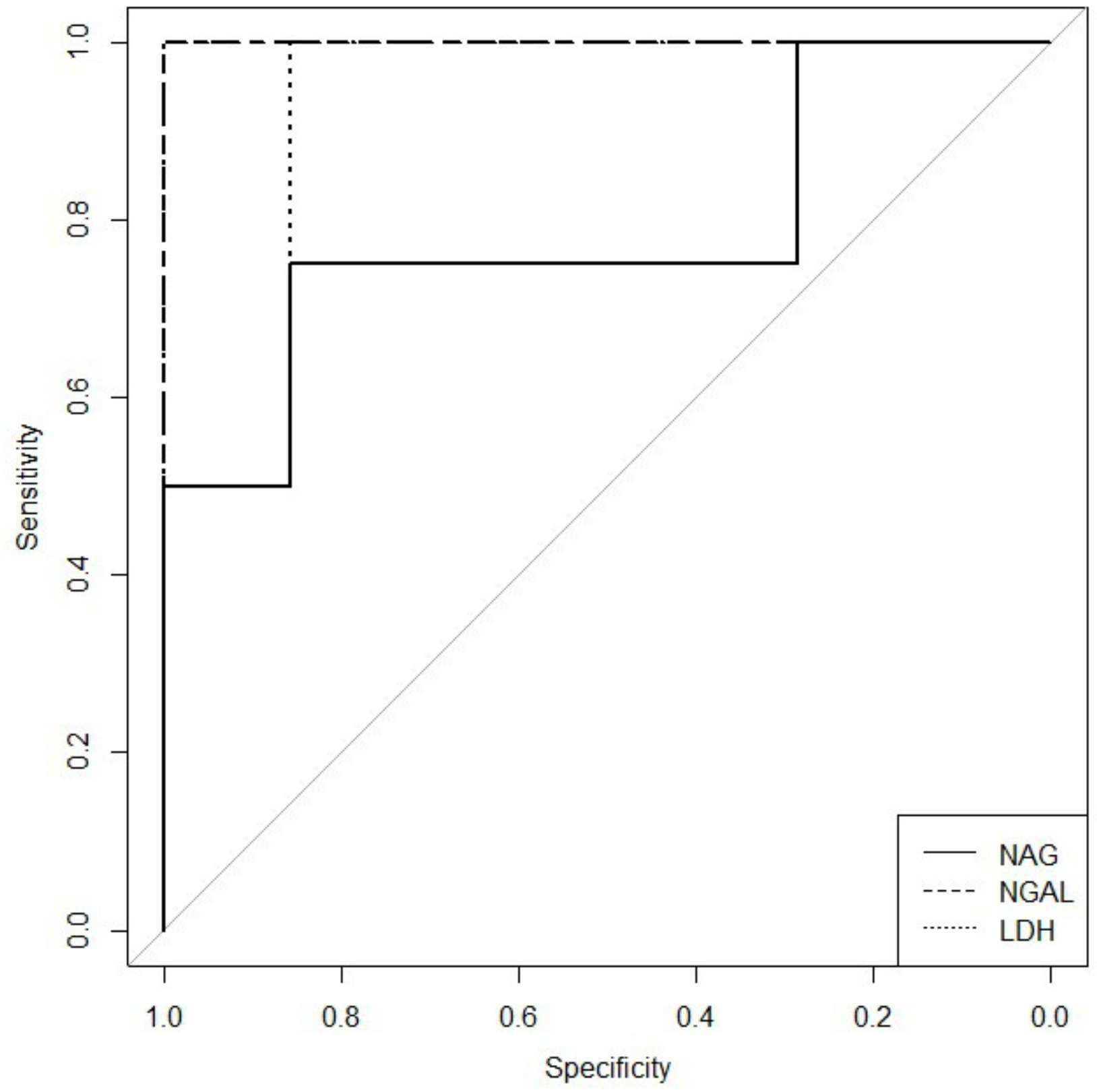





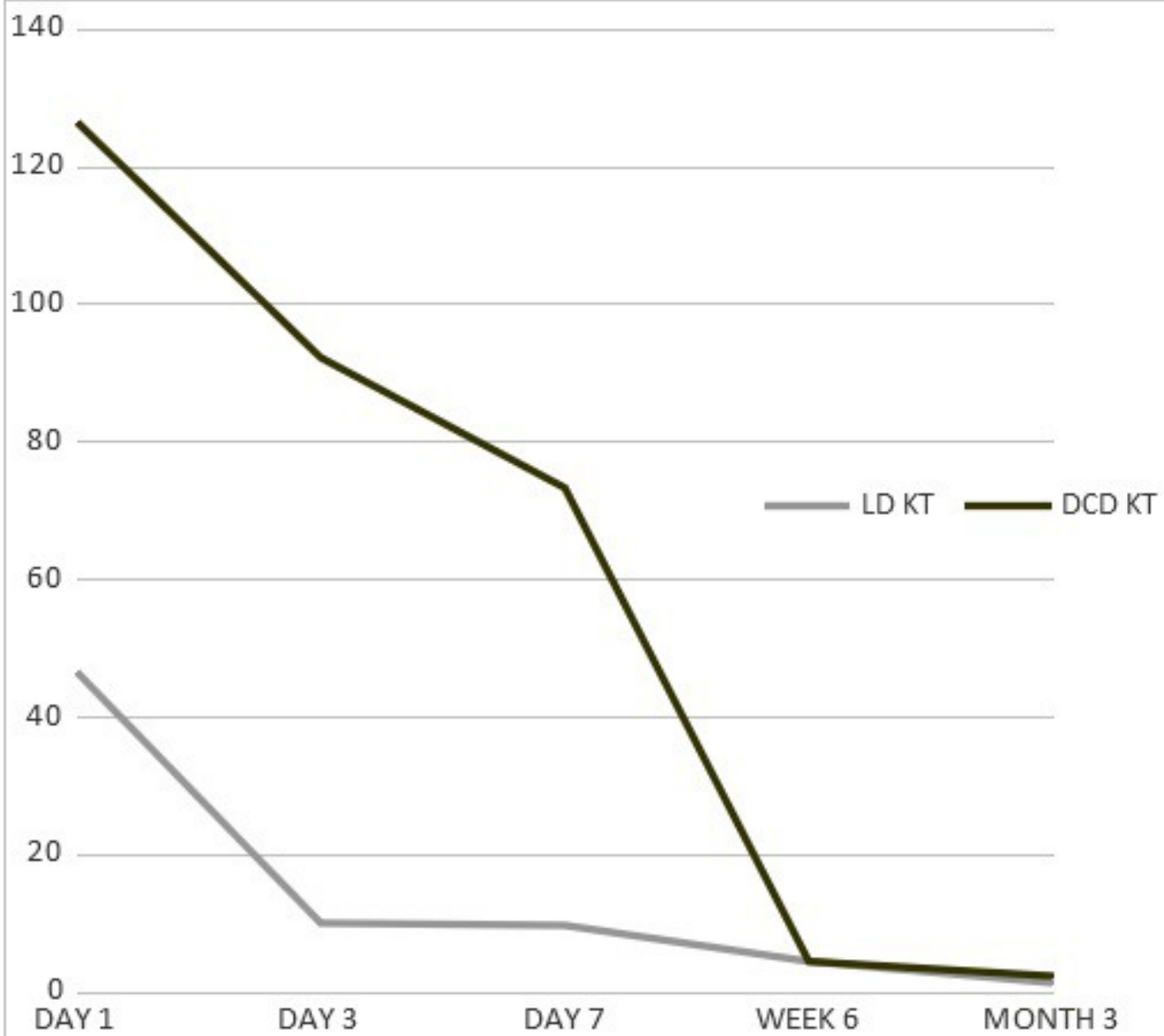

